\title{
Removal of Cholesterol from Blood by Affinity Binding to Heparin-Agarose: Evaluation on Treatment in Homozygous Familial Hypercholesterolemia
}

\author{
PAUL-J. LUPIEN, SITAL MOORJANI, MADELEINE LOU, DANIEL BRUN, AND CLAUDE GAGNÉ \\ Lipid Research Center, University Hospital and Department of Biochemistry, Faculty of Medicine, Laval University, \\ Quebec, Canada
}

\section{Summary}

Extracorporeal removal of cholesterol from blood with heparinagarose conjugates was studied as a means of reducing the plasma cholesterol concentration in two patients with homozygous familial hypercholesterolemia. Both patients were treated in an outpatient clinic. Patient 1 underwent two separate courses of treatment; during the first course of eight treatments, the plasma cholesterol concentration decreased by a maximum of 54\% (from 811-370 $\mathrm{mg} / \mathrm{dl})$. The six treatments in the second course resulted in a $35 \%$ reduction of plasma cholesterol (from $939-632 \mathrm{mg} / \mathrm{dl}$ ). In patient two, 12 consecutive treatments resulted in a $56 \%$ decrease in the concentration of plasma cholesterol (from $768-298 \mathrm{mg} / \mathrm{dl}$ ). Repetitive treatments in both patients resulted in a new "steady state" with circulating cholesterol levels lower than the pretreatment baseline value. The decrease in plasma cholesterol is mainly due to the removal of low density lipoproteins. The circulating level of high density lipoproteins is unaffected by the treatment. The treatment has no effect on the chemical composition of both low and high density lipoproteins. The extracorporeal treatment of blood with heparin-agarose was well tolerated by both patients and there were no undesirable effects. The effectiveness and simplicity of the present approach makes it attractive as a possible mode of therapy for homozygous familial hypercholesterolemia.

\section{Speculation}

Reduction of plasma cholesterol by the removal of low density lipoproteins in an extracorporeal system is described as a possible mode of therapy for homozygous familial hypercholesterolemia. The effective control of plasma low density lipoprotein level in these patients on long term basis, may permit to evaluate its effect on tissue deposits of cholesterol and atherosclerotic disease.

Homozygous familial hypercholesterolemia $(\mathrm{HFH})$ is characterized by a 4- to 6-fold increase in plasma total and low density lipoprotein (LDL) cholesterol (9). The genetic implications that lead to HFH have been reviewed by Goldstein and Brown (10); several sites and mechanisms appear to be involved. The deficiency of cell surface receptors for LDL as well as their defectiveness in binding LDL have been reported in cultured fibroblasts from patients with HFH (11). This defect in the binding of LDL is associated with impaired regulation of 3-hydroxy-3-methylglutaryl coenzyme A reductase (EC 1.1.1.34), a rate-limiting enzyme in the biosynthesis of cholesterol and decreased catabolism of LDL (10). Despite usual therapeutic measures, tendon and tuberous xanthomas develop in these patients in childhood and death from severe coronary atherosclerotic disease usually occurs before age $30(9,13)$. The authors have recently described a new approach in the management of familial hypercholesterolemia, based on the extracorporeal removal of lipoproteins by their affinity binding to heparin-agarose (17). In this communication, the repeated use of this treatment procedure in lowering plasma total and LDL cholesterol levels in two patients with HFH is reported. The preliminary findings reported here suggest that this form of therapy may find usefulness in the management of HFH, due to its lack of toxicity and significant lowering of both plasma and LDL cholesterol.

\section{MATERIALS AND METHODS}

\section{PATIENTS}

Two patients were studied after a written informed consent was obtained from the parents of both the patients. The presumptive diagnosis of $\mathrm{HFH}$ in these patients was based on the following criteria (9): (a) LDL cholesterol concentration was more than twice that of heterozygotes in the same kindred; (b) elevated LDL cholesterol in both parents or in the family line of an unavailable parent; (c) plasma LDL cholesterol concentration about $500 \mathrm{mg} /$ $\mathrm{dl}$; and (d) juvenile xanthomatosis.

Patient 1 was 3-yr-old at the time of treatment with heparinagarose and was first referred to the clinic when he was 6 months of age. Total plasma, very low density lipoprotein (VLDL), LDL, and high density lipoprotein (HDL) cholesterol levels were 960, 15,935 , and $10 \mathrm{mg} / \mathrm{dl}$, respectively. Agarose-gel electrophoresis showed a typical type IIa lipoprotein pattern. Planar xanthomas were noted on both Achiles tendons; other clinical and laboratory examinations were unremarkable. Screening of family members revealed parental cosanguanity and increased LDL cholesterol in both parents $(345$ and $188 \mathrm{mg} / \mathrm{dl}$ in father and mother aged 28 and $25 \mathrm{yr}$, respectively); the only brother, aged 5 years, had LDL cholesterol level of $221 \mathrm{mg} / \mathrm{dl}$. At follow-up visits, the patient showed progressive development of xanthomas despite diet and drug therapy with cholestyramine $(8 \mathrm{~g} /$ day). At $3 \mathrm{yr}$ of age, multiple tuberous xanthomas were observed on both knees, elbows, buttocks, dorsum of the hands and finger folds. Tendon xanthomas were present on the Achiles tendons and planar xanthomas were seen bilaterally in the popliteal fossae. Tubero-eruptive xanthomas were noted on the gluteal folds. A systolic murmur $(2 / 6)$ of vibratory quality was heard in the left parasternal area. Cholestyramine was discontinued 8 wk before treatment with heparin-agarose.

Patient 2 was 18-yr-old at the time of study. He was first examined in our clinic at the age of 15 and was known to have xanthomas since early childhood. The total plasma, VLDL, LDL, and HDL cholesterol levels were $647,19,599$, and $29 \mathrm{mg} / \mathrm{dl}$, respectively. On examination, gigantic tuberous xanthomas were seen on the knees, Achiles tendons, elbows, and dorsum of the 
hands. Tendon xanthomas were visible on the Achiles tendons and the extensors of all the fingers of both hands. Tubero-eruptive xanthomas were present on the buttocks. The patient's mother (41-yr-old) had total plasma, VLDL, LDL, and HDL cholesterol levels of $282,9,248$, and 26 , respectively. No data were available on the patient's father who died from heart disease at $46 \mathrm{yr}$ of age. The patient's three sisters aged 15,19 , and $22 \mathrm{yr}$ have total plasma cholesterol concentration of 156,294 , and $267 \mathrm{mg} / \mathrm{dl}$, respectively. Cardiovascular evaluation revealed the presence of a systolic murmur (2/6) in the aortic area of the heart. Bruit were heard (3/ 6 ) on both carotid arteries. The treadmill exercise test was normal. The patient was treated with nicotinic acid $(0.9-1.5 \mathrm{~g} /$ day) and cholestyramine ( $24 \mathrm{~g} /$ day) along with a diet low in cholesterol and saturated fatty acids for 3 yr before undergoing extracorporeal treatment with heparin-agarose during which both diet and drug therapy was continued.

\section{EXTRACORPOREAL TREATMENT OF BLOOD WITH HEPARIN- AGAROSE}

Batch chromatography was used for the extracorporeal delipidation of blood with heparin-agarose as described elsewhere (2, 17, 19). The preparation of heparin-agarose and its specificity for binding LDL and VLDL has been previously described (19). All treatments were carried out in the outpatient clinic. Each treatment lasted on an average from 2-3 hr after which the patient was released. In patient 1 , cholestyramine was discontinued 2 months before treatment where as patient 2 was taking nicotinic acid and cholestyramine throughout treatment. Blood and plasma volume was measured in both patients by radioiodine specific activity (1250 and $800 \mathrm{ml}$ in patient 1,4211 and $2665 \mathrm{ml}$ in patient 2). A catheter (Medicut, Sherwood Medical Industries, St. Louis, MO) was introduced in the anticubital vein and its tip connected to a four-way stopcock (Travenol Laboratories, Deerfield, IL). A transfer pack (Travenol Laboratories, Deerfield, IL) containing heparin (Harris Laboratories, Brantford, Ontario), heparin-agarose beads and calcium chloride was connected to the stopcock and 100 or $300 \mathrm{ml}$ of blood was drawn at a time, by gravity, in patients 1 and 2 , respectively. The contents of the blood pack were gently mixed and the blood was then returned to the circulation through a filter (Johnson and Johnson, New Brunswick, NJ) as in any standard transfusion. The lipoprotein-heparin-agarose complexes formed in the presence of calcium ions are retained by the transfusion filter. Approximately 13-25 g of heparin-agarose beads were reacted with every $100 \mathrm{ml}$ of blood withdrawn in the presence of calcium at a concentration of $0.02 \mathrm{M}$. In patient 1,600 units of heparin were used as anticoagulant and 1500 units in patient 2 . The heparin was added only in the first three transfusion packs; 60,30 , and $10 \%$ of the total dose in first, second, and third transfusion packs, respectively.

\section{BLOOD SAMPLES AND LABORATORY PROCEDURES}

Blood samples were withdrawn under appropriate conditions for various hematologic, lipid, and other clinical chemistry tests before and $10 \mathrm{~min}$ after the end of treatment. All blood analysis, except for the lipids, were performed by conventional methods as described previously (17).

In order to study the composition of various lipoprotein fractions, VLDL, LDL, and HDL wcre prepared by sequential ultracentrifugation in a L2-65B ultracentrifuge with 40.3 rotor (Beckman Instruments, Palo Alto, CA) according to the method described by Havel et al. (12). If only cholesterol was determined in the various lipoproteins, then the plasma fraction with a density of more than $1.006 \mathrm{~g} / \mathrm{ml}$ was analyzed, before and after precipitation with heparin and manganese (5) at a final concentration of 412 USP units/ml and $95 \mathrm{mM}$, respectively. LDL cholesterol was obtained by difference. Total cholesterol and triglycerides were measured after extraction with isopropanol using Technicon AutoAnalyzer II (22). Total and unesterified cholesterol were also measured enzymatically (21) using manual reagent kit (CHOD/ PAP, Boehringer Mannhein) and esterified cholesterol was cal- culated from the difference. Phospholipid was determined by the method of Zilversmit and Davis (26) and protein by the dyebinding method of Bradford (4) using crystalline Bovine serum albumin as a standard. Agarose gel electrophoresis of plasma lipoproteins was carried out by a modification of the procedure of Noble (20) as described previously (19). Plasma levels of apoprotein-B were determined by the rocket immunoelectrophoretic method of Laurell (14) using commercially prepared anti- $\beta$-lipoprotein serum (Behring diagnostics, Montreal, Québec). The immunoelectrophoresis was run at $2 \mathrm{~V} / \mathrm{cm}$ for $18 \mathrm{hr}$.

\section{RESULTS}

Patient 1 underwent two separate courses of extracorporeal treatments with heparin-agarose during which no lipid-lowering drugs were taken. Figure 1 summarizes the effects of repetitive treatments, on plasma cholesterol levels during the first course of eight treatments which lasted 20 days. Initially, $700 \mathrm{ml}$ of blood were delipidated with heparin-agarose $(100 \mathrm{ml}$ at a time) which resulted in the removal of $1.9 \mathrm{~g}$ of cholesterol and the plasma concentration of cholesterol was reduced by $30 \%$. With cessation of treatment, plasma cholesterol levels increased gradually and attained the baseline level after 7 days. A similar effect was observed during the next treatment except that the return to pretreatment levels occurred after 3 days. The subsequent five treatments were given at 1- to 2-day intervals and 300-500 ml of blood were delipidated at each treatment. These successive treatments resulted in a decrease in plasma cholesterol concentration from $768-370 \mathrm{mg} / \mathrm{dl}$. The maximum decrease in the plasma cholesterol concentration during the first course of eight treatments was $54 \%$ (from $811-370 \mathrm{mg} / \mathrm{dl}$ ); a total of $3150 \mathrm{ml}$ of blood was treated which resulted in a cumulative removal of $9.04 \mathrm{~g}$ of cholesterol.

Several months later, patient 1 underwent a second course of six treatments with heparin-agarose but this time at 2-wk intervals for 10 wk (Fig. 2). It will be noted that during the first three treatments, plasma cholesterol levels between treatments always returned back to pretreatment baseline values. However, during the last three treatments, plasma cholesterol levels did not regain their initial values but appeared to have reached a new threshold of steady-state which was approximately $200 \mathrm{mg} / \mathrm{dl}$ lower than observed in the earlier phases of treatment. A total of $3800 \mathrm{ml}$ of blood was treated which resulted in a cumulative removal of 6.4 $\mathrm{g}$ of cholesterol. Maximum decrease in plasma cholesterol was $35 \%$. No lipid lowering drug was given throughout the treatment period.

Patient 2 was treated with diet and drug therapy (cholestyramine

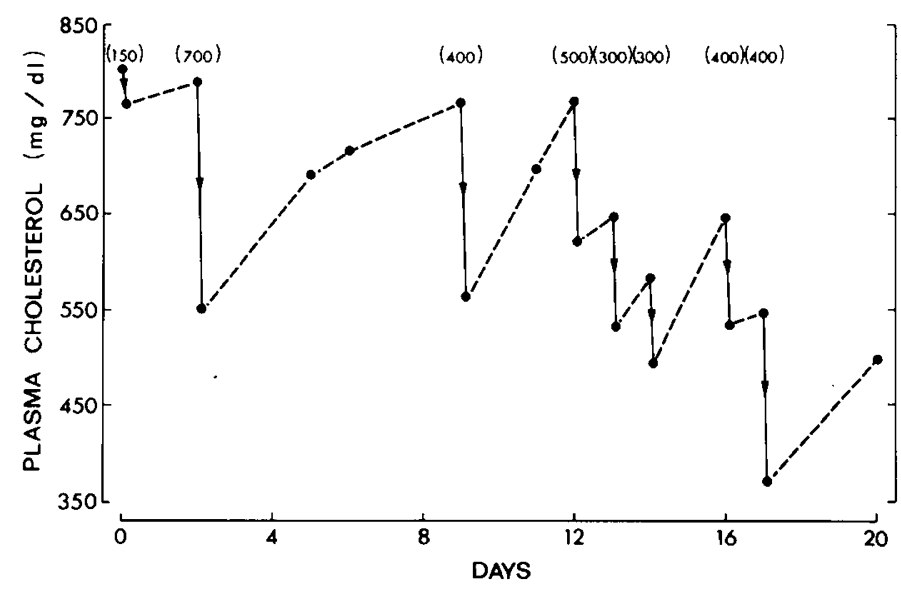

Fig. 1. Changes in plasma cholesterol concentration during the first course of extracorporeal removal of cholesterol from blood with heparinagarose in patient 1. Numbers in parenthesis at the top of the figure, cumulative blood volume treated in $\mathrm{ml}$ at each treatment. Solid lines with an arrow, plasma cholesterol values before and after the treatment. - - - , show the increase in cholesterol between treatment periods. 


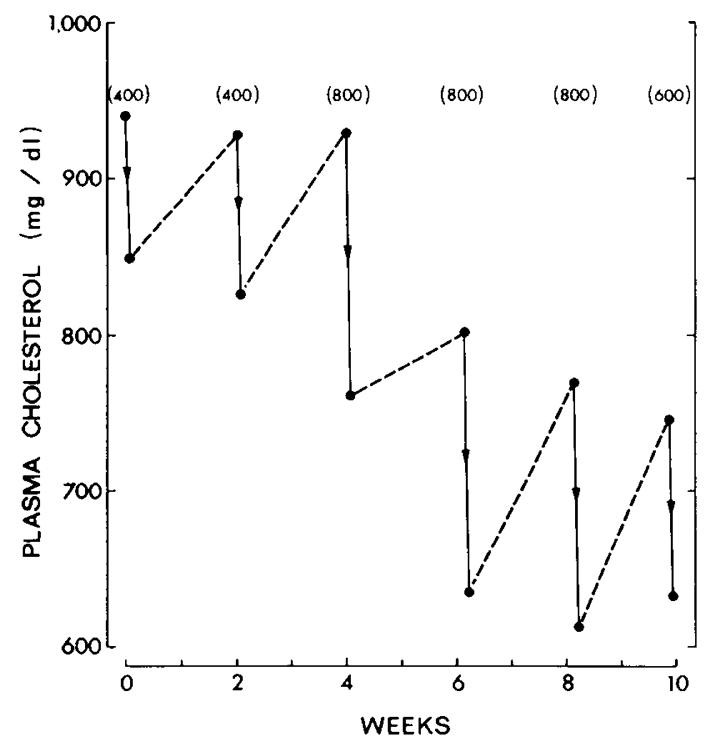

Fig. 2. Changes in plasma cholesterol concentration during the second course of extracorporeal removal of cholesterol from blood with heparinagarose in patient 1 . For other details, see legend to Figure 1.

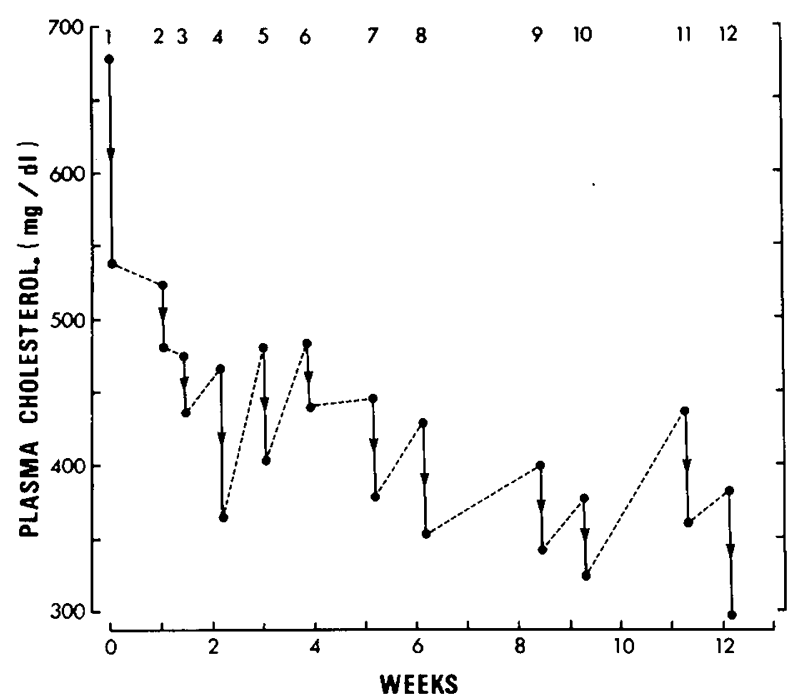

Fig. 3. Changes in plasma cholesterol concentration during extra-corporeal removal of cholesterol from blood with heparin-agarose in patient 2. Numbers at top, treatments; $1800 \mathrm{ml}$ of blood was delipidated at each treatment except treatments 1,4 , and 6 during which 3000 and $1200 \mathrm{ml}$ of blood were treated, respectively. For other details, see legend to Figure 1.

and nicotinic acid) for $3 \mathrm{yr}$ before he underwent extracorporeal treatment of blood with heparin-agarose; both drugs were continued during the study and the patient received 12 extracorporeal treatments. The results on plasma cholesterol levels are shown in Figure 3. Initially, $3000 \mathrm{ml}$ of blood were delipidated with heparinagarose $(300 \mathrm{ml}$ at a time) which resulted in the removal of $3.6 \mathrm{~g}$ of cholesterol and the plasma concentration of cholesterol was reduced by $21 \%$. One wk after treatment, plasma cholesterol concentrations had decreased instead of rising to baseline values as had been noticed in patient 1 . During subsequent treatments, the plasma cholesterol concentrations decreased further and the levels between treatments never reached pretreatment baseline values but rather remained approximately $250 \mathrm{mg}$ lower than the initial value. A total of $23,400 \mathrm{ml}$ of blood was delipidated in patient 2 during 12 treatments which resulted in the removal of $23.6 \mathrm{~g}$ of cholesterol; maximum decrease in plasma cholesterol was $56 \%$ (from $678-298 \mathrm{mg} \%$ ).

The effect of various treatments on the plasma concentration of cholesterol in both patients is summarized in Table 1. During the first and second course of treatment with heparin-agarose in patient 1 , a mean decrease of 28 and $11 \%$ is noticed as compared to average cholesterol concentration during 2-yr treatment with diet and cholestyramine. Similarily, in patient 2 , the mean cholesterol level during combined diet, drug and heparin-agarose treatment is $25 \%$ lower than the average cholesterol concentration observed during diet and drug therapy for a period of $3 \mathrm{yr}$.

A mean decrease of $18 \%$, per treatment, in the concentration of plasma cholesterol is similar to that of phospholipid as shown in Table 2. The lowering of plasma cholesterol level is mostly due to the decrease of LDL-cholesterol, because the concentration of HDL-cholesterol is virtually unaffected by the treatment. Although VLDL-cholesterol is greatly reduced during the treatment, its contribution to the overall reduction of plasma cholesterol is not appreciable due to low cholesterol content of this fraction. In fact, the decrease in VLDL-cholesterol as well as plasma triglycerides (Table 2) is more likely due to hydrolysis of triglycerides and conversion of VLDL into intermediary lipoprotein particles, by lipoprotein lipase which is released in the circulation by heparin

Table 1. Plasma cholesterol concentration during various treatments in patients 1 and $2^{1}$

\begin{tabular}{|c|c|c|c|}
\hline Treatment & $\mathbf{N}$ & $\begin{array}{l}\text { Cholesterol } \\
(\mathrm{mg} / \mathrm{dl})^{1}\end{array}$ & $P$ \\
\hline \multicolumn{4}{|l|}{ Patient 1} \\
\hline $\mathrm{Rx}$ & 13 & $\begin{array}{c}853 \pm 93 \\
(744-1,088)\end{array}$ & \\
\hline Heparin-agarose 1st treatment & 15 & $\begin{array}{l}612 \pm 120 \\
(310-788)\end{array}$ & $<0.001$ \\
\hline 2 nd treatment & 11 & $\begin{array}{l}757 \pm 104 \\
(632-929)\end{array}$ & $<0.05$ \\
\hline
\end{tabular}

Patient 2

$\mathrm{Rx}$

$16 \quad 525 \pm 68$

$R x+$ heparin-agarose $(450-678)$

$25 \quad 393 \pm 69$ $(298-537)$

${ }^{1}$ Values are mean $\pm 1 \mathrm{SD}$ for 2-yr period during Rx and for 3- and 10wk period during 1 st and 2 nd course of treatment with heparin-agarose in patient 1 . In patient 2 , the values are for 3-yr treatment period during $R x$ and for 12 wk during $R x+$ heparin-agarose. Values in parenthesis indicate range. $\mathrm{N}$ is number of observations. The statistical significance of differences between cholesterol values was analyzed by Student's $t$ test. For Rx, see Materials and Methods.

Table 2. Plasma lipid and lipoprotein levels before and after treatment with heparin-agarose in patient 2

\begin{tabular}{lccc}
\hline & $\begin{array}{c}\text { Initial }^{1} \\
(\mathrm{mg} / \mathrm{dl})\end{array}$ & $\begin{array}{c}\text { Final }^{2} \\
(\mathrm{mg} / \mathrm{dl})\end{array}$ & $P$ \\
\hline Cholesterol & $496 \pm 73$ & $\begin{array}{c}409 \pm 57 \\
(18)\end{array}$ & $<0.02$ \\
Triglycerides & $111 \pm 38$ & $\begin{array}{c}39 \pm 17 \\
(65)\end{array}$ & $<0.001$ \\
Phospholipids & $344 \pm 57$ & $\begin{array}{c}281 \pm 52 \\
(18)\end{array}$ & $<0.05$ \\
VLDL-cholesterol & $13 \pm 7$ & $\begin{array}{c}2 \pm 1 \\
(85)\end{array}$ & $<0.001$ \\
LDL-cholesterol & $452 \pm 65$ & $\begin{array}{c}379 \pm 55 \\
(16)\end{array}$ & $<0.05$ \\
HDL-cholesterol & $30 \pm 3$ & $29 \pm 3$ & N.S. \\
Aproprotein B & $206 \pm 22$ & $\begin{array}{c}164 \pm 17 \\
(20)\end{array}$ & $<0.005$ \\
\hline
\end{tabular}

\footnotetext{
${ }^{1}$ Values are mean $\pm 1 \mathrm{SD}$ for eight treatments; $1800 \mathrm{ml}$ of blood were delipidated at each treatment.

${ }^{2}$ Values in parentheses are percent decrease from the initial value. The statistical significance of differences between initial and final values was analyzed by Student's $t$ test.
} 
(9) used as an anticoagulant. However, some VLDL and intermediary lipoprotein particles may also be removed by heparinagarose, because it has been shown previously that VLDL also bind to heparin-agarose although it has lower affinity as compared to LDL (19). As shown in Table 2, a decrease of $20 \%$ in the plasma level of apoprotein B is higher than the $16 \%$ decrease in the concentration of LDL-cholesterol. These results further indicate that some VLDL is also being removed, which may explain a higher decrease in the plasma concentration of apoprotein B as compared to LDL-cholesterol.

The extracorporeal treatment of blood with heparin-agarose has no effect on the chemical composition of both LDL and HDL as shown in Table 3. Although the composition of VLDL is greatly modified (Table 3), it is unlikely that it may be caused by heparinagarose. The changes in the composition rather reflect the hydrolysis of VLDL by lipoprotein lipase activity as discussed earlier. The effect of extracorporeal treatment of blood with heparinagarose on serum calcium level and various hematologic determinations is presented in Table 4. It will be noted that in spite of the addition of exogenous calcium for the binding of $\mathrm{LDL}$ to heparin-agarose, the circulating concentration of calcium ions is not increased. This is due to the retention of calcium ions by heparin-agarose as shown previously in the in vitro studies (19). The heparin-agarose treatment resulted in a marginal decrease in erythrocyte counts, hemoglobin, hematocrit, and platelet counts. This effect is attributed to some loss of blood during repeated transfusions and also due to blood samples taken for various laboratory tests. The leucocyte count showed a small but significant increase during the treatment, which was transitory and always remained in the normal range. The increase in leukocyte count is accompanied by alterations in the distribution of neutrophils and lymphocytes, but the differences observed are small and not significant. These transient changes noticed during extracorporeal treatment of blood with heparin-agarose may be related to repeated withdrawl and reinfusion of blood. No significant alterations were seen in several routine clinical chemistry and immunologic tests as also described previously $(2,17,19)$. The increase in prothrombin time is, however, due to partial heparinization of the patient, as judged from mixing studies which did not show coagulation factor deficiency.

\section{DISCUSSION}

HFH is characterized by very high levels of plasma and LDL cholesterol and coronary atherosclerotic disease progresses very rapidly in these patients, whose average life expectancy is less than 20 yr (13). Dietary manipulations associated with combination drug therapy are usually without adequate response in the decrease of plasma cholesterol levels except in a few instances (7, $15,16)$. The data presented here clearly demonstrate that the plasma cholesterol concentration can be lowered in HFH patients by the extracorporeal removal of cholesterol through treatment with heparin-agarose. The results shown in Table 1 compare the effects of treatment with heparin-agarose to that of conventional diet and drug therapy. It will be noticed that an additional mean decrease of $11-28 \%$ is obtained over diet and drug therapy, during very short periods of treatment with heparin-agarose. The average removal of cholesterol from circulation per $100 \mathrm{ml}$ of blood treated, during the first and second course of treatment in patient 1, was 287 and $176 \mathrm{mg}$ as compared to $100 \mathrm{mg}$ in patient 2 . In two other patients (heterozygotes, type IIa) reported previously (17), an average of 176 and $150 \mathrm{mg}$ of cholesterol was removed per 100 $\mathrm{ml}$ of blood treated. These differences are probably due to varying proportion of heparin-agarose conjugates used in the treatment of blood in each case, as well as due to variation in the binding capacity of various heparin-agarose batches used in the treatment.

The data in patient 1 indicate that during the initial phase of treatment, there is a transient but substantial decrease in the concentration of plasma cholesterol which rapidly increases to baseline value upon cessation of treatment. However, with sustained treatments, the plasma cholesterol concentration decreased further and attained a new steady state, at a lower circulating level of cholesterol. Similar effects were noted in patient 2 except that the posttreatment cholesterol levels never reached the pretreatment value throughout the study. This difference may be attributed to the additional beneficiary effect of hypolipidemic drugs in this patient as also previously reported by Thompson et al. (24, 25).

The return of cholesterol to baseline value after cessation of extracorporeal removal of blood cholesterol, may result from increased synthesis of cholesterol or may be due to mobilization of tissue cholesterol. In a similar approach but using the plasma exchange technique, Thompson et al. $(19,20)$ have shown that reduction of plasma cholesterol by replacement of the patients plasma with cholesterol-free purified protein fraction resulted in an influx of tissue cholesterol into the plasma compartment. Plasmapheresis has been shown to lower plasma cholesterol concentrations in rats (21), with a concomitant increase in the plasma cholesterol during the postplasmapheresis period due to an increase in the rate of cholesterol synthesis. However, it was suggested that the increase in plasma concentration of cholesterol was due to an increased rate of protein and lipoprotein synthesis in response to protein depletion caused by plasmapheresis. Such a mechanism is unlikely to operate in the present approach, because plasma protein concentration is virtually unaffected by the extracorporeal removal of cholesterol with heparin-agarose.

The use of plasmapheresis and plasma exchange $(1,3,8,25)$ in the management of HFH patients has been suggested. This approach is different from the conventional plasmapheresis in that it is specific for the removal of LDL; although VLDL may be removed, there is no effect on the circulating levels of HDL. This finding is of particular interest, because it has been suggested that HDL may be involved in the regulation of tissue-cholesterol (18) and reduction in its concentration may accelerate the process of atherosclerosis. The extracorporeal treatment of blood with heparin-agarose was without side effects in both patients, as judged from routine physical examination as well as hematologic and biochemical tests. It has certain advantages over plasmapheresis

Table 3. Chemical composition of plasma lipoproteins before and after delipidation of blood with heparin-agarose in patient $2^{1}$

\begin{tabular}{|c|c|c|c|c|c|}
\hline & Protein & Phospholipid & Triglyceride & Cholesterol esters & Cholesterol (unesterified) \\
\hline \multicolumn{6}{|c|}{ Before treatment } \\
\hline VLDL & 10 & 26 & 41 & 18 & 6 \\
\hline LDL & 17 & 22 & 5 & 46 & 9 \\
\hline HDL & 51 & 21 & 5 & 22 & 2 \\
\hline \multicolumn{6}{|c|}{ After treatment } \\
\hline VLDL & 10 & 48 & 33 & 7 & 2 \\
\hline LDL & 17 & 23 & 4 & 45 & 10 \\
\hline HDL & 48 & 23 & 5 & 23 & 2 \\
\hline
\end{tabular}

1 Values are expressed as percent of the sum of all constituents analyzed. Values are mean of two determinations carried out in two separate treatments during which $1800 \mathrm{ml}$ of blood was delipidated. The mean decrease in the concentration was $17,52,15,75,15$, and $3 \%$ for cholesterol, triglyceride, phospholipid, VLDL, LDL, and HDL cholesterol, respectively. 
Table 4. Serum calcium levels and hematologic indices before and after extracorporeal treatment of blood with heparin-agarose in patient $2^{1}$

\begin{tabular}{lrccc}
\hline & $\mathrm{N}^{2}$ & Initial $^{3}$ & Final $^{3}$ & $\mathrm{P}$ \\
\hline Calcium (mg\%) & 12 & $9.9 \pm 0.4$ & $9.6 \pm 0.6$ & N.S. \\
Erythrocyte count & 12 & $4.4 \pm 0.3$ & $4.2 \pm 0.3$ & N.S. \\
$\quad\left(\times 10^{6}\right)$ & & & & \\
Hemoglobin (g\%) & 12 & $11.9 \pm 0.6$ & $11.5 \pm 0.6$ & N.S. \\
Hematocrit $(\%)$ & 12 & $34.9 \pm 1.8$ & $33.7 \pm 1.8$ & N.S. \\
Platelets $\left(\times 10^{3}\right)$ & 6 & $372 \pm 35$ & $360 \pm 37$ & N.S. \\
Leucocyte count $\left(\times 10^{3}\right)$ & 12 & $6.3 \pm 1.0$ & $8.2 \pm 2.1$ & $<0.02$ \\
Neutrophils $(\%)$ & 12 & $55.6 \pm 3.6$ & $53.4 \pm 9.5$ & N.S. \\
Lymphocytes $(\%)$ & 12 & $33.4 \pm 2.5$ & $37.2 \pm 8.2$ & N.S. \\
Prothrombin time $(\mathrm{sec})$ & 6 & $10.6 \pm 0.6$ & $14.4 \pm 0.9$ & $<0.01$ \\
\hline
\end{tabular}

${ }^{1}$ The following analyses were unaffected by the treatment: glucose, blood urea-nitrogen, total proteins, globulins, phosphorous, magnesium, uric acid, creatinine, sodium, potassium, chloride, alkaline phosphatase, lactic dehydrogenase, glutamic-oxaloacetic, and glutamic-pyruvic transaminases.

${ }^{2} \mathrm{~N}$ is number of observations, the statistical significance of differences between initial and final values was analyzed by Student's $t$ test.

${ }^{3}$ Values are mean $\pm 1 \mathrm{SD}$.

and plasma exchange, because it is selective in the removal of plasma LDL and VLDL and, furthermore, no exogenous plasma products are introduced that may lead to various complications (6). It is suggested that the present treatment procedure can be used more frequently and for longer periods than plasmapheresis and may serve as a useful mode of therapy for HFH patients.

\section{REFERENCES AND NOTES}

1. Apstein, C. S., Zilversmit, D. B., George, P. K., Feldman, H. A., and Lees, R.: Reduction of serum cholesterol with intensive plasmapheresis. Clin. Res., 22: 31 Ia (1974).

2. Awad, J. A., Lupien, P.-J., Moorjani, S., and Cloutier, R.: A simple method for the removal of undesirable substances from the blood: removal of plasma cholesterol. Curr. Ther. Res., 21: 525 (1977).

3. Berger, G. M. B., Miller, J. L., Bonnici, F., Joffe, H. S., and Dubovsky, D. W.: Continuous flow plasma exchange in the treatment of homozygous familial hypercholesterolemia. Amer. J. Med., 65: 243 (1978)

4. Bradford, M. M.: A rapid and sensitive method for the quantitation of microgram quantities of protein utilizing the principle of protein-dye binding. Anal. Biochem., 72: 248 (1976).

5. Burstein, M., and Samaille, J.: Sur un dosage rapide du cholestérol lié aux $\alpha$ - et aux $\beta$-lipoprotéines du sérum. Clin. Chim. Acta, 5: 509 (1960).

6. Buskard, N. A.: Plasma exchange and plasmapheresis. Can. Med. Assoc. J., 119: 681 (1978).

7. Buxtorf, J. C., Beaumont, V., Jacotot, B., and Beaumont, J. L.: Regression de xanthomes et médicaments hypolipidémiants. Athrosclerosis, 17: 1 (1974)

8. DeGennes, J. L., Touraine, R., Maunand, B., Tuffert, J., and Laudat, P.: Formes homozygotes cutanéo-tendineuses de xanthomatose hypercholestérolémique dans une observation familiale exemplaire. Essai de plasmaphérèse à titre de traitement héroique. Bull. Soc. Méd. Hôp. Paris, 118: 1377 (1967).

9. Fredrickson, D. S., Goldstein, J. L., and Brown, M. S.: The familial hyperlipoproteinemias, In: J. B. Stanbury, J. B. Wyndaarden, and D. S. Frederickson: Metabolic Basis of Inherited Diseases, 3rd ed., p. 604 (McGraw Hill Inc., New York, 1978)

10. Goldstein, J. L., and Brown, M. S.: Atherosclerosis: the low density lipoprotein receptor hypothesis. Metabolism, 26: 1257 (1977).

11. Goldstein, J. L., Dana, S. E., Brunschede, G. Y., and Brown, M. S.: Genetic heterogenity in familial hypercholesterolemia: evidence for two different mutations affecting functions of low density lipoprotein receptor. Proc. Natl. Acad. Sci. USA, 72: 1092 (1975).

12. Havel, R. J., Eder, H. A., and Bragdon, J. H.: The distribution and chemical composition of ultracentrifugally separated lipoproteins in human serum. J. Clin. Invest., 34: 1345 (1955).

13. Khachadurian, A. K., and Uthman, S. M.: Experiences with the homozygous cases of familial hypercholesterolemia. Nutr. Metab., 15: 132 (1973).

14. Laurell, C. B.: Quantitative estimation of proteins by electrophoresis in agarose gel containing antibodies. Anal. Biochem., 15: 45 (1966).

15. Levy, R. I., Fredrickson, D. S., Schulman, R., Bilheimer, D. W., Breslow, J. L., Stone, N. J., Lux, S. E., Sloan, H. R., Krauss, R. M., and Herbert, P. N.: Dietary and drug treatment of primary hyperlipoproteinemia. Ann. Intern. Med., 77: 267 (1972).

16. Lupien, P.-J., Brun, D., and Moorjani, S.: Long-term treatment of homozygous familial hypercholesterolemia with 3-hydroxy-3-methylglutaric acid. Lancet, 1: 283 (1978)

17. Lupien, P.-J., Moorjani, S., and Awad, J.: A new approach to the management of familial hypercholesterolemia: removal of plasma cholesterol based on the principle of affinity chromatography. Lancet, I: 1261 (1976).

18. Miller, G. J., and Miller, N. E.: Plasma high density lipoprotein concentration and development of ischaemic heart disease. Lancet, 1: 16 (1975).

19. Moorjani, S., Lupien, P.-J., and Awad, J. A.: Extracorporeal removal of plasma lipoproteins by affinity binding to heparin-agarose. Clin. Chim. Acta, 77: 21 (1977).

20. Noble, R. P.: Electrophoretic separation of plasma lipoproteins in agarose gels. J. Lipid. Res., 9: 693 (1968).

21. Richmond, W.: Use of cholesterol oxidase for assay of total and free cholesterol in serum by continuous-flow analysis. Clin. Chem., 22: 1579 (1976).

22. Rush, R. L., Leon, L., and Turrell, J.: Automated simultaneous cholesterol and triglyceride determinations on the AutoAnalyzer II instrument, In: Advances in Automated Analysis, p. 503 (Thurman Association, Miami, 1971).

23. Takeuchi, N., and Yamamura, Y.: The effect of plasmapheresis on cholesterol synthesis in the rat. J. Lab. Clin. Med., 79: 801 (1972).

24. Thompson, G. R., Kilpatrick, D., Raphael, M., Oakley, C., and Myant, N. B.: Use of plasma exchange to induce regression of atheroma in familial hypercholesterolemia. Eur. J. Clin. Invest., 7: 233 (1977)

25. Thompson, G. R., Lowenthal, R., and Myant, N. B.: Plasma exchange in the management of homozygous familial hypercholesterolemia. Lancet, 1: 1208, 1975.

26. Zilversmit, D. B., and Davis, A. W.: Microdetermination of plasma phospholipids by trichloroacetic acid precipitation. J. Lab. Clin. Med., 35: 155 (1950).

27. The authors thank the staff of Lipid Research Center, especially Mrs. R. Boisvert for technical assistance; Mrs. N. Mordret and Mrs. H. Bernier for their participation in the treatment of patients, and Mrs. S. Parent for secretarial help.

28. Requests for reprints should be addressed to: P.-J. Lupien, Professor and Director, Lipid Research Center, Laval University Hospital, 2705 Boulevard Laurier, Ste-Foy, Québec, Canada GlV 4G2.

29. Received for publication June 6, 1978 .

30. Accepted for publication March 14, 1979. 